\title{
The family journey-to-diagnosis with systemic juvenile idiopathic arthritis: a cross-sectional study of the changing social media presence
}

This article was published in the following Dove Press journal:

Open Access Rheumatology: Research and Reviews

26 May 2016

Number of times this article has been viewed

\author{
Renee F Modica' \\ Kathleen Graham Lomax ${ }^{2}$ \\ Pamela Batzel ${ }^{3}$ \\ Leah Shapardanis ${ }^{3}$ \\ Kimberly Compton Katzer ${ }^{3}$ \\ Melissa E Elder' \\ 'Division of Pediatric Rheumatology, \\ Immunology and Infectious Diseases, \\ University of Florida, Gainesville, \\ $\mathrm{FL}, \mathrm{USA} ;{ }^{2}$ Immunology and \\ Dermatology Medical Affairs, Novartis \\ Pharmaceuticals Corporation, East \\ Hanover, USA; ${ }^{3}$ Treato, Princeton, NJ, \\ USA
}

Background: Children with systemic juvenile idiopathic arthritis (SJIA) often encounter a delay between symptom onset and disease diagnosis, partly due to the broad differential of fever and lack of symptom recognition by providers. Families often seek multiple medical opinions and post on social media about their frustrations. This linguistic analysis observed the changing language patterns and social media posting behaviors of parents in the time leading to, during, and after SJIA diagnosis.

Methods: Public social media sites were manually reviewed by a linguistic team to evaluate posts about SJIA from US-based parents.

Results: A total of 3,979 posts between July 2001 and January 2015 were reviewed from 108 sites. Pre-SJIA diagnosis parents sought answers and shared status updates on social media, focusing primarily on the following three site types: alternative/natural lifestyle forums (39\%), Facebook (27\%), and disease-specific forums (17\%). Posts during early prediagnosis phases were characterized by expressive language showing confidence in health care providers and trust in parental instincts. At later prediagnosis stages, parents continued to use social media, but the posts demonstrated increased frustration with delays in diagnosis and gaps in communication with providers. More objective symptom descriptions and a greatly reduced child-centered emotional focus were observed as parents shifted into caregiving roles. Once the diagnosis of SJIA was confirmed, parents used straightforward, less expressive language, and Facebook (47\%) to make "announcement" posts and increased their use of SJIA websites (30\%). With treatment initiation, the posts demonstrated a slow return of expressive language and an increased parental understanding of the "new normal".

Conclusion: Parents use different language styles, frames of reference, and websites before and after SJIA diagnosis. Gaps in parent-provider communication, especially before diagnosis, and their new roles as caregivers lead to parental use of social media to express frustration with the health care process. Providers should tailor their discussions with parents to address these issues.

Keywords: systemic juvenile idiopathic arthritis, social media, linguistics, language frames, diagnostic process

\section{Background}

Juvenile idiopathic arthritis is the most common chronic rheumatic disease in children, covering a range of autoimmune and inflammatory disorders. ${ }^{1}$ Systemic juvenile idiopathic arthritis (SJIA) is the most acute and severe of this group. The International League of Associations for Rheumatology (ILAR) classify SJIA as the presence of arthritis in one or more joints with, or preceded by, fever of at least 2 weeks' 
duration, which is documented to be daily (quotidian) for at least 3 days and accompanied by one or more of the following: evanescent erythematous rash, generalized lymph node enlargement, hepatomegaly, and/or splenomegaly or serositis. ${ }^{2}$ SJIA can present at any time until the age of 16 years, but more than half of the cases occur between the ages of 0 year and 5 years, with 2 years being the most common age of presentation. ${ }^{3}$

The systemic symptoms of SJIA are often more significant at disease onset than arthritis, and the broad differential of fever of unknown origin can sometimes lead to misdiagnosis as an infectious disease. ${ }^{1,3}$ Although distinct ILAR diagnostic criteria for SJIA exist, only one-third of all patients fulfill these criteria at onset. ${ }^{1}$ This incomplete presentation combined with a lack of provider recognition can result in SJIA being undiagnosed for weeks/months after symptom onset. Delays in SJIA diagnosis trigger families to seek multiple medical opinions and post on social media to voice their frustrations and to gain advice from those who have encountered similar experiences.

This linguistic analysis presents the observations in the changing language patterns and social media posting behaviors of parents before, during, and after the diagnosis of SJIA. The objective of this study was to develop an understanding of families' emotional and practical "journey-todiagnosis," based on parental online discussions, including parents of children with potential SJIA (based on symptoms reported in posts), as well as posts from parents of recently diagnosed children and parents of diagnosed children who reflect back on their journey-to-diagnosis. We aimed to understand where parents go online to discuss a potential or confirmed SJIA diagnosis.
Study design and patient population

A cross-sectional observational study was conducted between January 2015 and March 2015, where a linguistic analysis team (Treato, Princeton, NJ, USA) manually evaluated the language and posting behaviors of parents and caregivers of children with SJIA. The analysis team included a trained linguist and a medical anthropologist. Posts that did not fulfill the criteria established by the rating scheme in Figure 1 were excluded. The primary dataset was obtained from existing, publically available sites and posts (ie, posts viewable by all and not requiring a password to access), and was limited to English language public social media with exclusion of posters that were evidently outside the US Rating scale criteria created to evaluate prediagnosed SJIA (Figure 1). The distinctions between early and late prediagnosed children and the ratings of tentatively diagnosed children are listed in Figure 2.

Treato's proprietary technology was used to identify and categorize social media health care discussions, using various databases (including proprietary dictionaries) and natural language processing. Using these technology capabilities, Treato created two project-specific datasets, one capturing discussions among families with a child diagnosed with SJIA and the other capturing discussions among families with an undiagnosed child but signaling that the child may have SJIA. Each dataset included multiple inclusion and exclusion criteria. Manual review of a cross section of the posts from each of the two datasets was performed, with analysts confirming the relevance (ie, SJIA diagnosis in the former and true signals of potential SJIA in the latter). For the manual analysis of the undiagnosed posts, the linguistic team used a system to categorize the posts on the likelihood of SJIA (Figure 1), using diagnostic criteria from the ILAR classification ${ }^{2}$ and

\begin{tabular}{|c|c|c|c|c|}
\hline 1 & 2 & 3 & 4 & 5 \\
\hline $\begin{array}{l}\text { Prolonged } \\
\text { occurrence of } \\
\text { two symptoms }\end{array}$ & $\begin{array}{l}\text { Prolonged } \\
\text { occurrence of } \\
\text { three or more } \\
\text { symptoms } \\
\text { or recurrence of } \\
\text { two or more } \\
\text { symptoms }\end{array}$ & $\begin{array}{l}\text { Increased duration } \\
\text { with at least one } \\
\text { recurrence of two } \\
\text { or more symptoms; } \\
\text { two or more visits } \\
\text { to a doctor or } \\
\text { hospital }\end{array}$ & $\begin{array}{l}\text { Increased duration } \\
\text { with more than one } \\
\text { recurrence; three } \\
\text { or more symptoms; } \\
\text { multiple visits to } \\
\text { varied } \\
\text { providers }\end{array}$ & $\begin{array}{l}\text { Increased duration with } \\
\text { multiple recurrences } \\
\text { suggestive to periodic fever; } \\
\text { three or more symptoms; } \\
\text { multiple visits to } \\
\text { providers; family history; } \\
\text { failed or atypical differential } \\
\text { diagnoses or treatment(s) }\end{array}$ \\
\hline \multicolumn{5}{|c|}{ The following symptoms were included in the patient evidence rating } \\
\hline $\begin{array}{l}\text { Fever } \\
\text { - Rash }\end{array}$ & \multicolumn{3}{|c|}{$\begin{array}{l}\text { - Joint pain/stiffness } \\
\text { - Standard pain indicators } \\
\text { for preverbal and } \\
\text { nonverbal children } \\
\text { - Growing pain }\end{array}$} & $\begin{array}{l}\text { Inactivity or malaise } \\
\text { Appetite abnormalities, } \\
\text { oral ulcers and diarrhea } \\
\text { when concurrent with } \\
\text { above primary symptoms }\end{array}$ \\
\hline
\end{tabular}

Figure I Rating scale criteria used for evaluation of prediagnosis posts. 


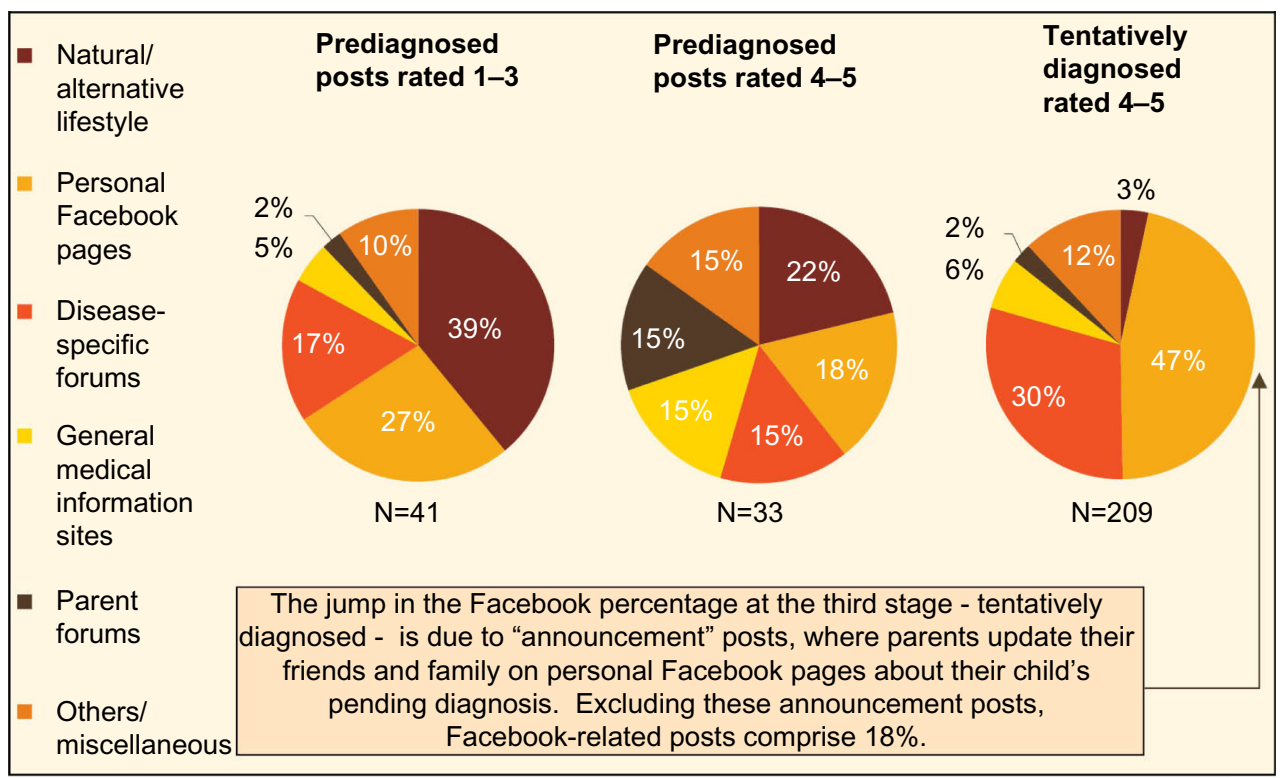

Figure 2 Website selections during the patient journey.

guidelines for diagnosis from the American College of Rheumatology (ACR). ${ }^{4}$

Analysis of the posts focused on two main periods: prediagnosis (posts mentioning a suspected and tentative diagnosis - early and late phases) and postdiagnosis (posts mentioning a confirmed SJIA diagnosis). The prediagnosis period was further subdivided into early and late phases based on the language used in the posts. The linguistic team created the prediagnosis and postdiagnosis datasets of social media user-generated content where parents were explicitly discussing their child's SJIA or there was evidence that they were discussing potential SJIA. The prediagnosis posts were evaluated using the evidence rating scale shown in Figure 1.
This was an observational, post-hoc analysis therefore no ethical approval or informed consent was obtained as posts were retrieved from public, open access websites.

\section{Results}

A total of 3,979 posts were reviewed from 108 sites with a date range from July 10, 2001 to January 7, 2015. A total of 1,005 posts were included in this analysis due to their relevance to a possible diagnosis of SJIA. Of these, 283 posts were consistent with prediagnosed SJIA children and 722 posts involved confirmed postSJIA diagnosed children, as shown in the flow diagram in Figure 3.

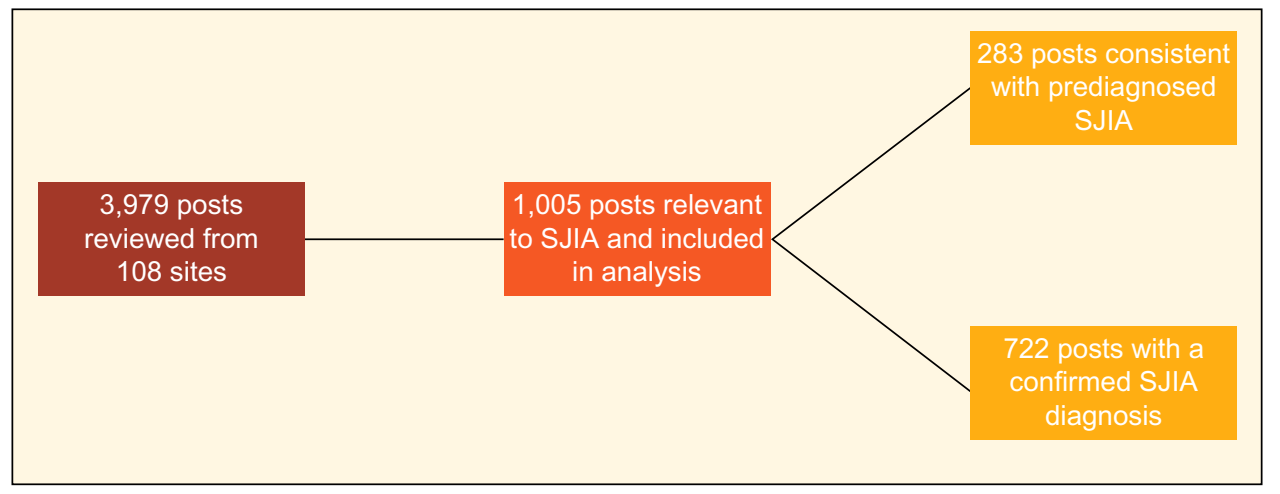

Figure 3 Analysis of reviewed posts.

Abbreviation: SJIA, systemic juvenile idiopathic arthritis. 


\section{Website selections change throughout the SJIA journey}

Our analysis of posting behavior indicates that parent choices of website change during the early-to-late prediagnosis phase. During early prediagnosis (ratings 1-3), the following three social media sites/categories were in particular focus: alternative/natural lifestyle forums (39\%), Facebook (27\%), and disease-specific forums $(17 \%)$, as shown in Figure 2. During later prediagnosis stages (ratings 4-5), parents posted to alternative/ natural lifestyle forums (22\%) and Facebook (18\%), with remaining posts equally shared between disease-specific SJIA forums (15\%), medical information sites (15\%), parenting forums (15\%), and other sites (15\%). Once a tentative diagnosis of SJIA was made (ratings 4-5), there was a large increase in posts being made to Facebook (47\%) to make announcements and to disease-specific sites $(30 \%)$.

\section{Early prediagnosis phase (ratings I-3)}

During the early prediagnosis phase, parental language is intuitive, emotive, and expressive, demonstrating confidence in the treatment provided by the health care providers. Parents are confident in their relationship with their child and trust their natural parental intuition and instincts. Parents discuss their child's illness intuitively, explaining that they "feel" something is not right or they "think" there is more to their child's illness. Figure 4 provides an example of the parental language used during this period. This use of language demonstrates that when parents are confident in their relationship with their child - and their role as a parent - they feel comfortable with relying on what they know and feel intuitively.

\section{Late prediagnosis phase (ratings 4-5)}

As time passed without diagnosis during late prediagnosis phases, parental language shifted to an "investigator" mode as parents began to doubt their provider's ability to correctly diagnose their child. The reliance on parental intuition was undermined by providers who parents felt lacked concern or sometimes dismissed them as "worriers" or repeatedly sent them home without answers. Parents felt their reliance on their own intuition was compromised by providers who "didn't seem too concerned" as their concern increased. Parents tempered their emotions so they were not dismissed again as "the crazy Mom". Of all posts that related to switching providers, the exclusive reason for this switch was due to parental concerns being "dismissed". Parent-provider interactions that resulted in parents feeling their concerns were being dismissed appeared to drive changes in parental focus from their child and their intuition to the disease itself. During this change, parents shifted from use of expressive language focused on their child to clear, objective language focused on measuring and reporting symptoms without mention of intuition, as seen in Figure 5.

As parents' roles shifted from an emotional, childcentered "parent" focus to a more objective "caregiver" focus, later posts demonstrated a similar change to more objective narratives of symptoms observed with reduction or absence of expressive language.

After diagnosis, parents often reflected back on what led to delays in diagnosis and often cited "dismissal of their child's symptoms as growing pains". "Growing pains" were mentioned 262 times, with 185 of them indicating symptom dismissal. Parents indicated that the majority of dismissals $(72 \%)$ were by the provider, with their own dismissals accounting for the remainder.

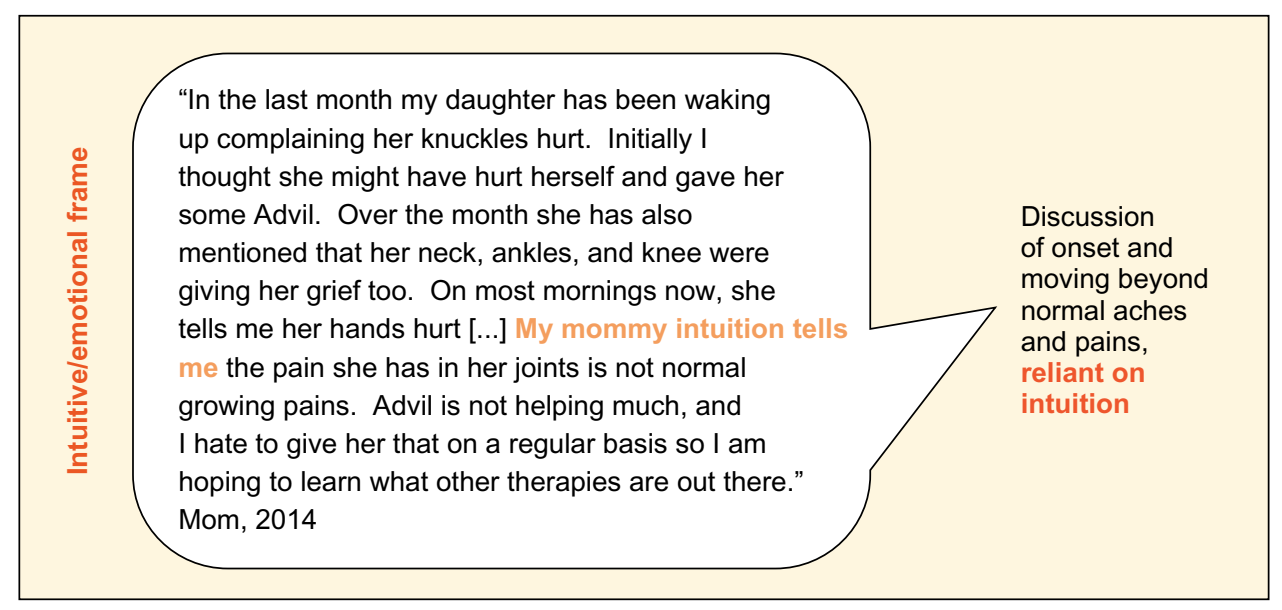

Figure 4 Example of intuitive and emotional language of parents: quote at disease onset (early prediagnosis phase). Note: The orange font is to highlight key words and important information from the quote. 


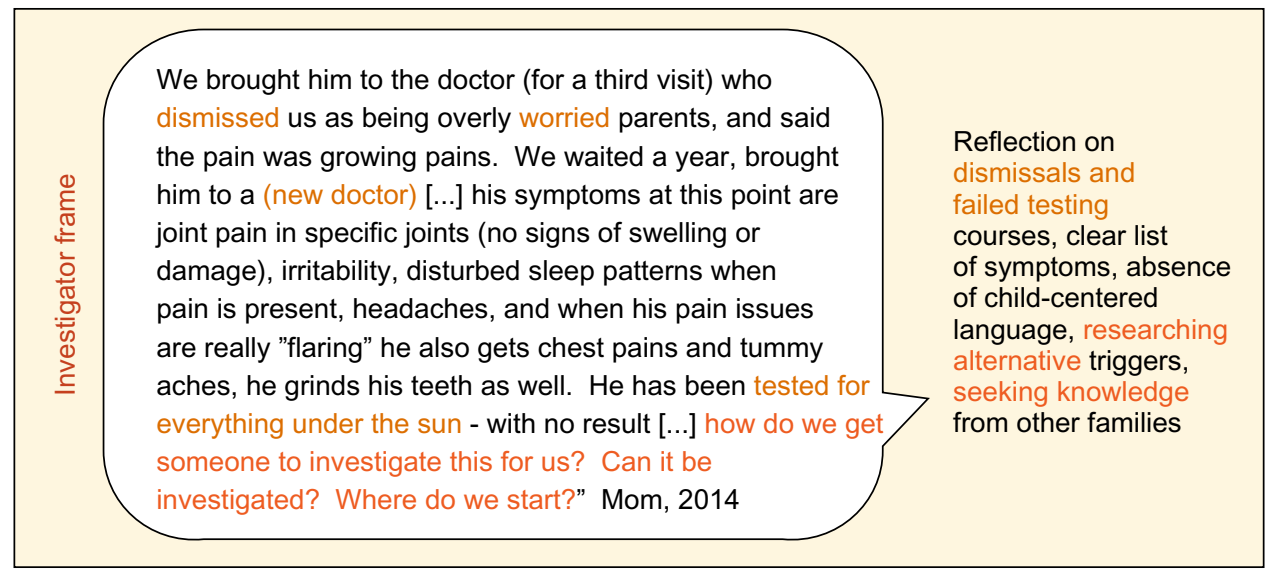

Figure 5 Example of investigative parental language: quote from late prediagnosis phase (very symptomatic undiagnosed child). Note: The orange font is to highlight key words and important information from the quote.

\section{Diagnosis phase}

A significant, but short and transient period of dry, straightforward, scientific language was used in parents' posts following the diagnosis, as shown in Figure 6. When the provider finally confirmed the diagnosis of SJIA, parents briefly retreated emotionally from their child and the situation. Many announcement posts simply stated the diagnosis. Immediately following the diagnosis, parents also renegotiated the parent-provider relationship, and a remarkable shift in the language occurred, indicating a change to a "relationship of equals". Parents exhibited transition from dismay with medicine and the health care process to developing a cooperative relationship with their provider where they discussed, evaluated, and decided on the treatment approaches and lifestyle changes in conjunction with their provider. Thus, their stance and linguistic frame during this phase continued to be as investigators.

\section{Postdiagnosis}

In the period following SJIA diagnosis, language expressing dismay or frustration with their provider was almost absent as parents aimed to achieve a partnership and work cooperatively with them. However, they also continued to actively develop an understanding of the disease for themselves and, importantly, of the available treatment options through social media. Information from other parents' experiences, analogies, and anecdotes was sought, as shown in Figure 7. They were not necessarily asking for

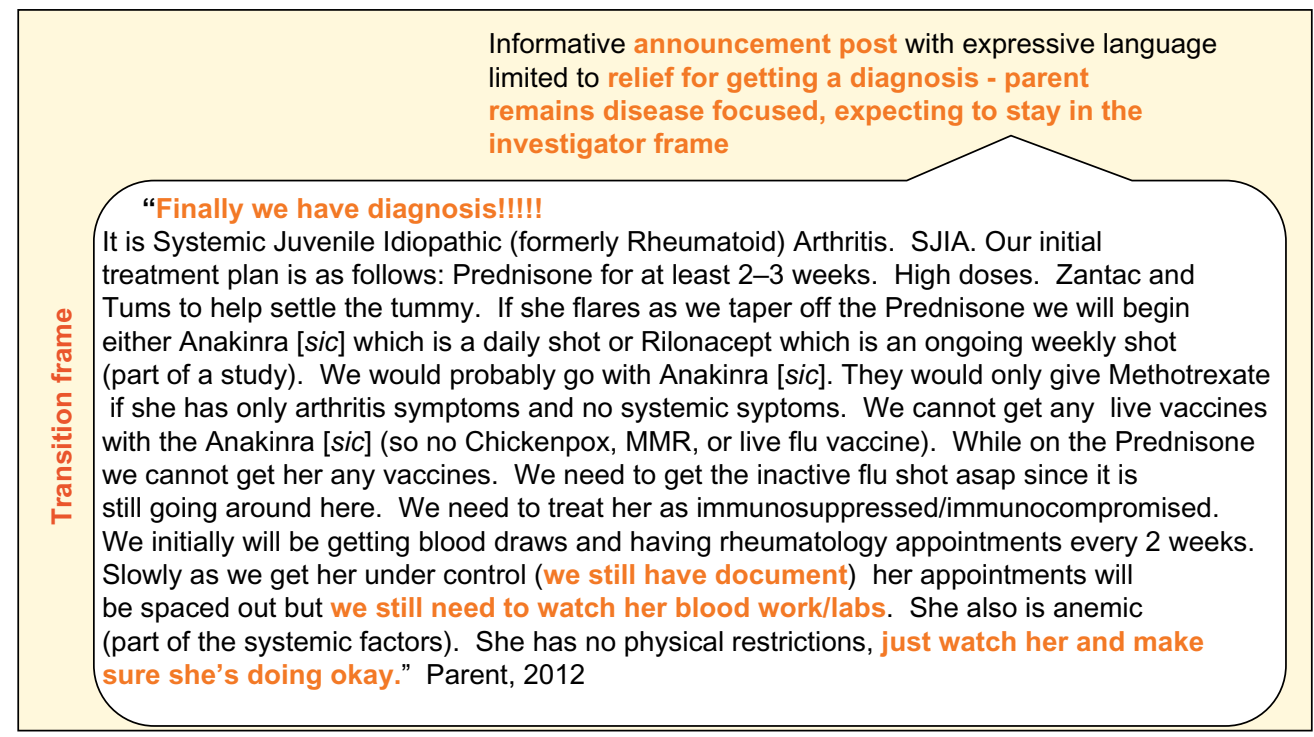

Figure 6 Example of announcement language: quote at diagnosis.

Note: The orange font is to highlight key words and important information from the quote.

Abbreviations: MMR, Measles, Mumps, and Rubella; asap, as soon as possible. 


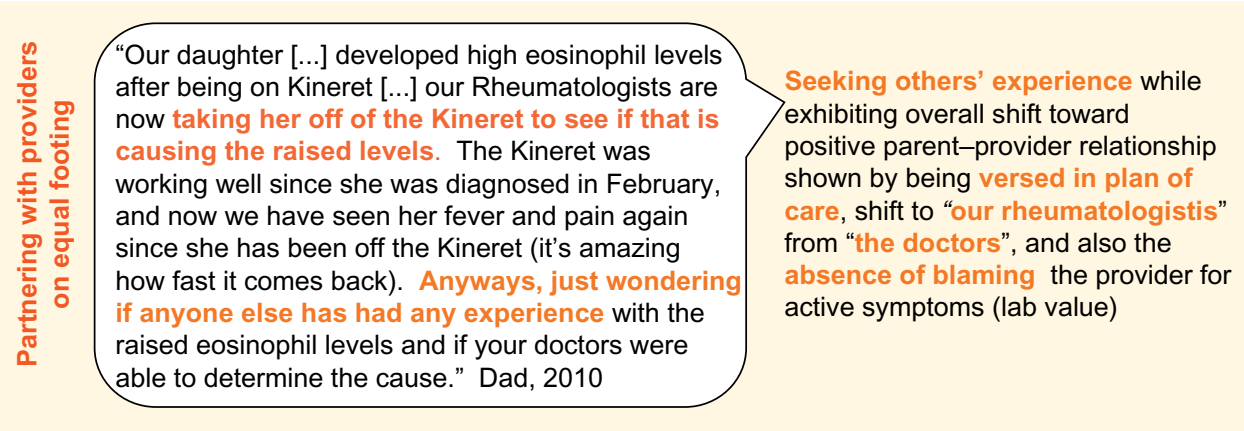

Figure 7 Example of postdiagnosis posts: investigators turn stalwart observers and provider partners.

Note: The orange font is to highlight key words and important information from the quote.

advice, but for information that they could use to further assess their own child. The expressive language previously used returned, but to a lesser degree, with continued use of objective language, which reflected a fundamental shift in the parents' identities from when they first sought diagnosis, as shown in Figure 8. In fact, parental language never returned to the original parent frame prior to disease onset, indicating that the disease process not only changed their child, but also changed them.

\section{End of postdiagnosis phase - parent- investigator mixed stage}

When a diagnosis had been reached, parents were often exhausted and had little or no emotional resources left, as shown in Figure 9. This was the beginning of the next parallel cycle: determining the appropriate acute treatment and maintenance strategies, wrought with many of the same challenges and difficulties as those in the diagnosis process. With a diagnosis of SJIA and a treatment plan in place for their child, parental language was cautiously optimistic. Parents whose children had already failed one treatment showed in their posts one of two attitudes: cautious optimism, in which they prepared for the worst when yet another medication failed or, hope that this next medication would be the right one, as shown in Figure 10. The language used in this phase indicated creation of a "new normal".

\section{Shifting ideas of a new normal}

Along with the cyclical transition between parentinvestigator-health care provider roles shown in Figure 11, there were shifting ideas of what defines normal. This follows five stages (Table 1), with each parent moving through the stages in their own time.

Parents appeared to shift back through the stages when disease flare-ups occurred, always with the intention of returning to a normative state where possible.

\section{Clinical relevance of these data and suggestions on how to implement these findings in clinical practice}

In the data presented here, we assessed the language choices that parents made in the clinical setting so that providers may

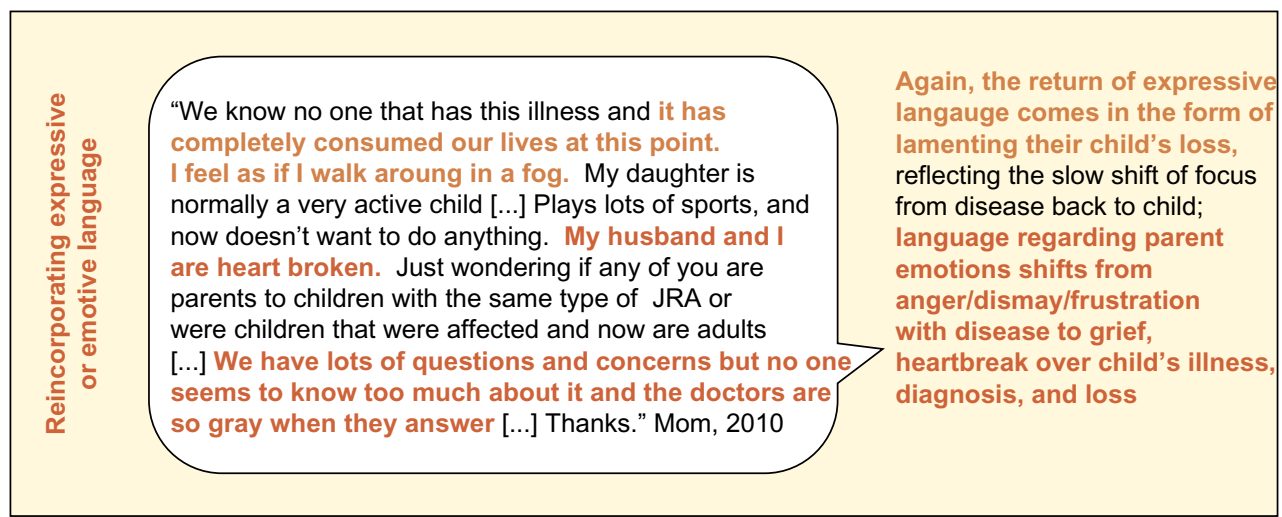

Figure 8 Example of postdiagnosis posts: reincorporating expressive language.

Note: The orange font is to highlight key words and important information from the quote.

Abbreviation: JRA, juvenile rheumatoid arthritis. 
"I was so concerned at what the future would hold for him. I was confused at why it was happening to him, I was angry, I was worried [...] I went through so many emotions, and often still do, so I understand how you must be feeling." Mom, 2005

Figure 9 Diagnostic journey: parent's frame after diagnosis is wrought with emotions and concerns for the future.

Note: The orange font is to highlight key words and important information from the quote.

better understand parents' cognitive frame - ie, how they are orienting to the illness, the provider, the diagnostic status, and their child. In doing so, providers may be able to address the motivations and focus of parents more directly. This research also suggests that the language and higher level messages that practitioners and other members of the clinical care team use should be directed toward the role and the practical stance of the parent. Recognizing and determining these shifting cyclical roles will help providers and the clinical care team "meet parents where they are". The ultimate goal is to smooth communication and enhance parent-provider relationships in order to effectively diagnose, explain, and inform treatment decisions. Smooth communication should be a team approach and be optimized not only from the provider but also from all members of the clinical care team as well as office staff in order to foster confidence between families who have been on this diagnostic journey with their new treatment team.

The overarching finding from this observational study is that the primary need of parents whose children are diagnosed with SJIA is support. Many parents lack community support and often feel that they lack the support of their primary health care provider. Parents may respond by shifting to objective observational language in the hope that they can recruit the attention of a knowledgeable provider who will help determine why their child is sick. However, some parents may not be able to make that shift and continue to present as a parent who intuitively know their child is sick. In either case, the language paints a picture of the parents' cognitive frame, which can guide the provider's responses to give best parental reassurance and support. This can lead to a greater trust, which supports the path to diagnosis and allows follow-up care where providers and the entire clinical care team and parents are aligned and share goals. ${ }^{5}$

Based on our analysis of online conversations, one of the most difficult aspects expressed by parents during the SJIA journey-to-diagnosis is loss and change of their identities, roles, and perspectives, as well as adjusting to a new normal for their family. The language studied in this analysis indicates that, as parents shift through the various stages of diagnosis, transference may arise between parents and providers. This is indicated by parents who picked up language and methods of care that were clinician-like. The degree of transference that occurs in clinical practice will clearly depend upon the individuals and personalities, but navigating

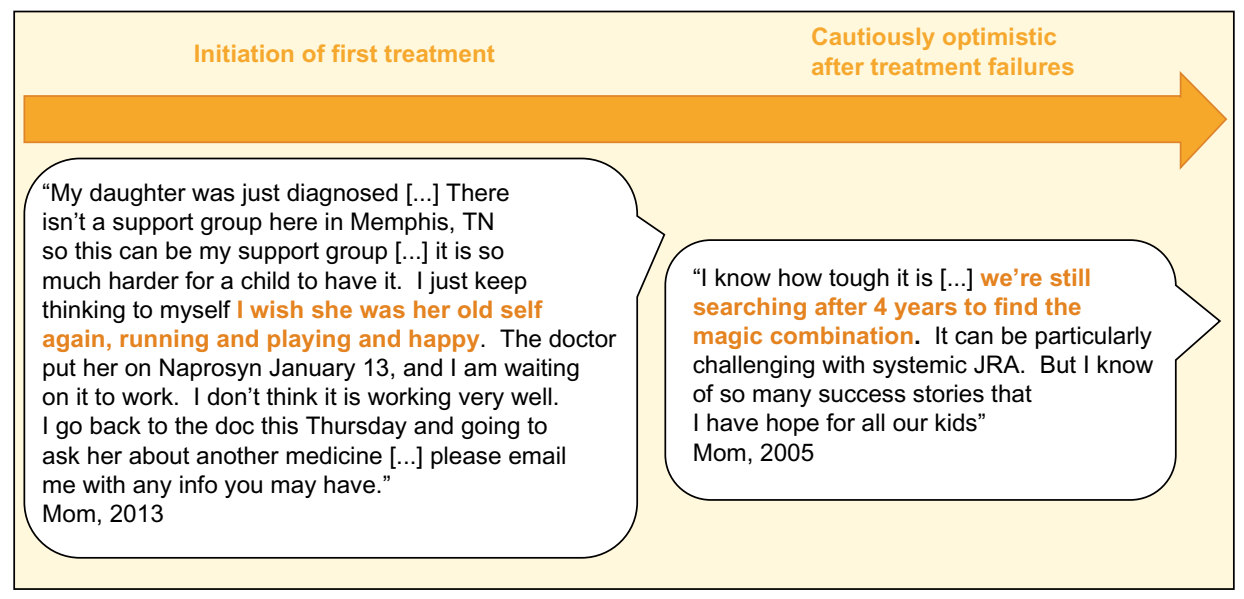

Figure 10 The mixed parent-investigator frame: examples of expressive language and creation of a new normal.

Note: The orange font is to highlight key words and important information from the quote.

Abbreviations: JRA, juvenile rheumatoid arthritis; doc, doctor; info, information. 


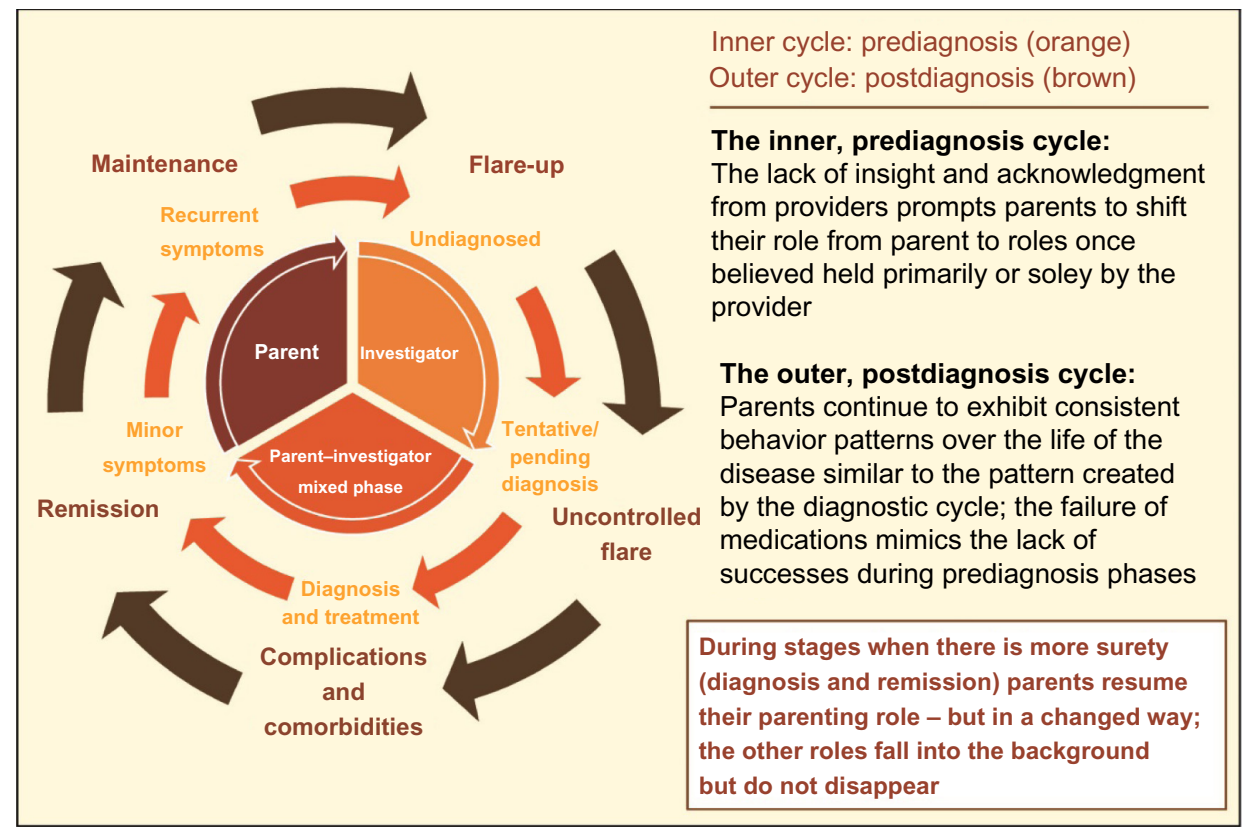

Figure I I Cyclical roles prompted by parental psychological experience and practical stance during the phases of diagnosis.

this delicate interaction is challenging. A supportive parental partnership with their provider can help stabilize a more traditional parent role, rather than delimiting their role to that of parent-investigator to a sick child. The pediatric rheumatologist and other members of the clinical team can help parents feel more secure during the diagnostic and treatment process by acknowledging parents' frustrations and fostering a partnership of trust and communication, and by being realistic with goals and expectations. Thus, specialists play a pivotal role in helping to make space between parents and their child's disease so that parents will begin to refocus their emotional energy on their child.

The use of these data in clinical practice can be categorized by the frame of the parent and the disease phase in the diagnosis cycle as shown in Table 2.

Language cues from parents (Table 2) can be used to help identify the parent frame, which can help inform the provider which stage the parent is currently in. These frame-directed

Table I Five stages of a new normal

I. Beginning: ideal for their normal happy/healthy child prior to onset of symptoms

2. Shift to a sick and changed child: parents wish they had their old child back

3. Diagnosis: period of grieving as parents adjusted to the fact things would never go back to the normal state

4. Search for a working treatment: expectations of normal are lowered

5. Medical treatment: parents shift to new normal and enter an adjustment period where they learn to regulate their child's activities responses will help reassure parents that their situations are understood, resulting in improved communication and parental trust. The goal is that parents are then better able to focus on providing answers needed to make an SJIA diagnosis and pursue appropriate treatments. The language that the parents use offers cues for the provider to better understand the family frame of mind in order to guide the best responses.

For parents with markers of the early journey parent, using more emotional, reassuring language before discussing the clinical aspects of the situation may help ease parents' anxieties so that they can focus on learning about SJIA and what they need to know about their child's situation.

For parents in an objective, investigative frame, it may be better to first address the diagnostic and treatment plan and only subsequently acknowledge that the search for diagnosis and the diagnosis of SJIA itself are emotionally taxing and disruptive. Table 3 offers suggestions on the use of provider language - but can be useful for all members of the clinical team - depending on the parent frame and the stage of SJIA.

In addition to the language recommendations described earlier, parroting or mirroring can be a helpful mechanism for cooperative alignment. This practice can reinforce the practitioner's investment in the family as well as allow for corrections when the parent feels what is being echoed back is not what they meant.

Furthermore, identifying the analogies to explain difficult concepts about autoimmune disorders is useful in 
Table 2 Language examples by parent frame ${ }^{\mathrm{a}}$

\begin{tabular}{|c|c|c|}
\hline $\begin{array}{l}\text { Early prediagnosis (and postdiagnosis } \\
\text { in remission or controlled disease } \\
\text { state) }\end{array}$ & $\begin{array}{l}\text { Late prediagnosis (and postdiagnosis } \\
\text { during an uncontrolled disease state) }\end{array}$ & $\begin{array}{l}\text { Newly diagnosed (and postdiagnosed } \\
\text { changing treatments, active disease } \\
\text { state) }\end{array}$ \\
\hline $\begin{array}{l}\text { The parent frame } \\
\text { Child at disease onset; early in the } \\
\text { diagnosis process, parents are emotionally } \\
\text { present, child-centered, and focused on } \\
\text { the whole child's well-being }\end{array}$ & $\begin{array}{l}\text { The investigator frame } \\
\text { Highly symptomatic, undiagnosed child; } \\
\text { parents feel dismissed, emotionally dry, } \\
\text { and use disease and symptom-centered } \\
\text { language and focus on getting a diagnosis }\end{array}$ & $\begin{array}{l}\text { The mixed frame } \\
\text { Child newly diagnosed; parents retain the } \\
\text { markers of investigator phase with the } \\
\text { restoration of earlier parent language and } \\
\text { begin forming a positive relationship with the } \\
\text { rheumatologist }\end{array}$ \\
\hline $\begin{array}{l}\text { Reliance on a parent's intuition } \\
\text { I know he's sick } \\
\text { He is not himself } \\
\text { I didn't take his temperature, } \\
\text { but I could tell he was warm }\end{array}$ & $\begin{array}{l}\text { Reliance on fact } \\
\text { She had a fever last week, and it was } \\
103.1^{\circ} \mathrm{F} \text { and lasted } 2 \text { days, and I gave her } \\
200 \mathrm{mg} \text { Motrin every } 6 \text { hours, but it } \\
\text { didn't do anything } \\
\text { Her fever last week lasted } 3 \text { days, } \\
\text { Monday-Wednesday, and it was } \\
\text { between } 101^{\circ} \mathrm{F} \text { and } 102.2^{\circ} \mathrm{F} \text { each night } \\
\text { for } 5 \text { hours } \\
\text { The rash shows up on the outside } \\
\text { of his ankle after the fever every time }\end{array}$ & $\begin{array}{l}\text { Reliance on facts and the whole child } \\
\text { Medicine X makes her sleepy and cranky } \\
\text { for } 2 \text { days, but I haven't noticed a rash } \\
\text { since October } 23 \\
\text { She's doing pretty good, she loves to swim, } \\
\text { and I think it's helping, but l've noticed she } \\
\text { sometimes favors her right knee } \\
\text { He had to miss a sleepover party last } \\
\text { month because his left knee was red, } \\
\text { warm, and swollen right here (pointing) } \\
\text { for } 2 \text { days after he went hiking }\end{array}$ \\
\hline $\begin{array}{l}\text { Nonspecific language and uncertainty } \\
\text { regarding symptoms } \\
\text { Often, sometimes, maybe, I guess, } \\
\text { I think, so, very, really, totally } \\
\text { (versus direct statements of fact) }\end{array}$ & $\begin{array}{l}\text { Specific language and certainty regarding } \\
\text { symptoms } \\
\text { She has, the fever will, it is, the pain is, } \\
\text { her rashes are }\end{array}$ & $\begin{array}{l}\text { Mix of specific language and seeking HCP } \\
\text { opinion to ground certainty } \\
\text { I'm just not sure that it's working } \\
\text { anymore, so I wanted to talk with you } \\
\text { about whether it might be time to switch } \\
\text { I feel like this pain in her knees might be } \\
\text { just a flare-up because she was at a party a } \\
\text { couple of weeks ago, but I am concerned } \\
\text { because it's been I0 days now. What do } \\
\text { you think? }\end{array}$ \\
\hline $\begin{array}{l}\text { Direct voice to parents' emotions } \\
\text { I was so scared } \\
\text { I'm worried } \\
\text { It freaked me out }\end{array}$ & $\begin{array}{l}\text { Emotions expressed as frustration } \\
\text { I just want this figured out } \\
\text { This is exhausting/concerning/confusing } \\
\text { Why isn't anyone doing anything? }\end{array}$ & $\begin{array}{l}\text { Emotive language begins to return after a } \\
\text { diagnosis but slowly and cautiously } \\
\text { I am feeling like we are on a path to } \\
\text { recovery } \\
\text { I am a bit worried that the medication } \\
\text { might not be doing enough } \\
\text { I am concerned that she is still in pain }\end{array}$ \\
\hline $\begin{array}{l}\text { Talks about the child as a whole person } \\
\text { Andrea isn't herself }\end{array}$ & $\begin{array}{l}\text { Focus shifts from child to factual evidence } \\
\text { of symptoms/disease } \\
\text { His knees are swollen and hurt } \\
\text { Her skin has rashes, and her joints hurt }\end{array}$ & $\begin{array}{l}\text { Attention to the whole child returns - } \\
\text { particularly as parents feel more reassured } \\
\text { that they are on the right treatment path } \\
\text { She's back to her old ways! } \\
\text { My boy is back }\end{array}$ \\
\hline
\end{tabular}

Note: aNote that the examples of language that a parent uses in the physician's office is extrapolated from how their language shifts in online discussions with other parents.

Abbreviation: $\mathrm{HCP}$, healthcare provider.

clinical practice to help parents make the leap into this new world.

Clinicians may find it useful to share these findings with both clinical and nonclinical members of the patient care team. The suggestions in Table 3 are designed specifically for rheumatologists but can be easily adapted by residents, medical technicians, and other clinical providers. A review of this data can also help other clinical providers better understand what may seem like inconsistent or muted parent emotion and allow them to empathize during their interaction(s) with the patient and family. While not all members of the office or patient care team will have the exposure to parent language as prolific as an interview, a sensitivity to these concepts will likely inform better patient/office communications, especially at the beginning of the patient/office relationship when setting the appointment for an initial consultation and upon entering the office for the first time. 
Table 3 Suggested use of clinician language depending on the parent frame and stage of the SJIA journey

\begin{tabular}{|c|c|c|}
\hline $\begin{array}{l}\text { Early prediagnosis (and postdiagnosis } \\
\text { in remission or controlled disease } \\
\text { state) }\end{array}$ & $\begin{array}{l}\text { Late prediagnosis (and postdiagnosis } \\
\text { during an uncontrolled disease state) }\end{array}$ & $\begin{array}{l}\text { Newly diagnosed (and postdiagnosed } \\
\text { changing treatments, active disease } \\
\text { state) }\end{array}$ \\
\hline $\begin{array}{l}\text { The parent frame } \\
\text { Child at disease onset; early in the } \\
\text { diagnosis process, parents are emotionally } \\
\text { present, child-centered, and focused on } \\
\text { the whole child's well-being }\end{array}$ & $\begin{array}{l}\text { The investigator frame } \\
\text { Highly symptomatic, undiagnosed child; } \\
\text { parents feel dismissed, emotionally dry, } \\
\text { and use disease and symptom-centered } \\
\text { language and focus on getting a } \\
\text { diagnosis }\end{array}$ & $\begin{array}{l}\text { The mixed frame } \\
\text { Child newly diagnosed; parents retain the } \\
\text { markers of investigator phase with the } \\
\text { restoration of earlier parent language and } \\
\text { begin forming a positive relationship with } \\
\text { the rheumatologist }\end{array}$ \\
\hline $\begin{array}{l}\text { Validate emotions } \\
\text { Concern for your child is natural, and you } \\
\text { are on the right track }\end{array}$ & $\begin{array}{l}\text { Validate information } \\
\text { Thank you for this information, and it will } \\
\text { certainly help us get to the bottom of this }\end{array}$ & $\begin{array}{l}\text { Validate emotions } \\
\text { Getting a final diagnosis is relieving, but } \\
\text { it's also intimidating, and I know you have } \\
\text { a lot of questions }\end{array}$ \\
\hline $\begin{array}{l}\text { Child-centered language } \\
\text { I want Bobby to try to walk/rest more/eat } \\
\text { pineapple }\end{array}$ & $\begin{array}{l}\text { Medically centered language } \\
\text { What I can see from your records is that } \\
\text { Bobby isn't really responding to Motrin, } \\
\text { and his swelling is worse at night }\end{array}$ & $\begin{array}{l}\text { Action-centered language } \\
\text { This is what I'm going to do; this is what } \\
\text { you're going to do (discuss the plan). } \\
\text { In the meantime, l'd like you to also go } \\
\text { online and reach out to families that have } \\
\text { experienced this process for support }\end{array}$ \\
\hline $\begin{array}{l}\text { Expressive language } \\
\text { That's a pretty involved rash, let's totally } \\
\text { cover all the bases here }\end{array}$ & $\begin{array}{l}\text { Goal-centered language } \\
\text { From here, this is the plan }\end{array}$ & $\begin{array}{l}\text { Goal-centered language } \\
\text { Our goal is to get Amanda's }[\ldots] \\
\text { (incorporate realistic goals and explain } \\
\text { that the degree of remission varies even } \\
\text { while being optimistic) }\end{array}$ \\
\hline $\begin{array}{l}\text { Affirm and partner } \\
\text { This might take a while to diagnose. } \\
\text { I want you to trust your gut because you } \\
\text { know Bobby best, but also I want you to } \\
\text { start a journal to track fevers and other } \\
\text { symptoms. Remember to write your } \\
\text { questions down for our next visit }\end{array}$ & $\begin{array}{l}\text { Partner } \\
\text { Keep documenting and email the data } \\
\text { and any questions you have for us a week } \\
\text { before your next visit }\end{array}$ & $\begin{array}{l}\text { Invite and validate questions } \\
\text { What questions do you have for me? }\end{array}$ \\
\hline $\begin{array}{l}\text { Goal-centered language } \\
\text { My goal is to get to the bottom of this. It } \\
\text { may take some time, but we will figure out } \\
\text { what is going on with Bobby }\end{array}$ & $\begin{array}{l}\text { Validate } \\
\text { I know this has been difficult, and you're } \\
\text { doing a great job. Keep doing what } \\
\text { you're doing, and we'll get this ironed out } \\
\text { together }\end{array}$ & $\begin{array}{l}\text { Reinforce partnership } \\
\text { Keep documenting and bring your } \\
\text { questions for me because not every child, } \\
\text { or every case of SJIA, is the same. Make } \\
\text { the distinction between child and the } \\
\text { disease. We'll work together to get the } \\
\text { right treatment going }\end{array}$ \\
\hline
\end{tabular}

Abbreviation: SJIA, systemic juvenile idiopathic arthritis.

\section{Conclusion}

Our analysis of social media posts revealed issues associated with SJIA diagnosis, including the prolonged time taken before diagnosis is confirmed in many children, its complex course, and its impact on parent-child and parent-provider relationships. The extensive presence of parents' posts about SJIA on social media provides key indicators about the stages throughout the diagnostic journey and how the parental frame of mind changes. Our analysis indicates that parents use different websites and post using different languages during SJIA prediagnosis versus postdiagnosis, emphasizing gaps in parent-provider communication.
A limitation of this study is its cross-sectional nature, which was not designed to allow particular children and parents to be followed over time, and thus, it was not possible to track parents as they moved between online posting boards, ie, pretreatment and posttreatment posts were not matched. It is likely that the posts were biased toward children with more protracted diagnostic journeys, since families experiencing diagnostic delays would be more frustrated than those diagnosed promptly and therefore more likely to post about their frustrations. It is also likely that the posts were biased toward parents who are proficient in using the Internet and who do so regularly to acquire information. As this study was cross sectional in nature, 
it was not possible to follow patients/posters over time, and it was also conceivable that a single post could have misidentified the disease stage that the patient was in. Similarly, since we were relying on social media posts without confirmation from medical records or communication with the posters or treating physicians, it is possible that the determination for inclusion or exclusion was inaccurate. A final limitation is that we incorporated the diagnostic criteria from the ILAR classification system and ACR diagnostic criteria to identify the posts likely to be relevant to SJIA, but these diagnostic systems do not identify $100 \%$ of affected patients, so it is possible that patients with true SJIA were excluded in error. ${ }^{1}$

Importantly, postdiagnosis parental language in social media postings never returned to the original linguistic parent frame prior to disease onset, demonstrating that the diagnostic process changes not only the child but also the parent. Furthermore, a parent's role changes from parent to caregiver as well as investigator, and this relationship fluctuates throughout the disease course and treatment process, particularly when disease flare-ups occur. Parents continue to actively develop an understanding of SJIA and available treatment options through social media after they have received SJIA diagnosis in order to better understand the disease and to avail themselves of a support network.

Providers should tailor their language and advice depending on the stage in disease diagnosis, treatment, and the parent frame. To this end, we have provided recommendations on language that can be used to engage with parents at different stages in the diagnostic/treatment process.

\section{Acknowledgments}

The authors thank Sylvia Shubert (Novartis Pharmaceuticals Corporation, East Hanover, NJ, USA) for research support.
The authors additionally thank Gillian Brodie, Rachel Cruickshank, and Mary-Kate Connolly (Novartis, Dublin, Ireland) for editorial support. This research was funded by Novartis Pharmaceuticals Corporation.

\section{Disclosure}

KGL is an employee of the Novartis Pharmaceuticals Corporation. RFM, PB, LS, KCK, and MEE report no conflicts of interest in this work. The authors had full control of the contents of this article.

\section{References}

1. Bruck N, Schnabel A, Hedrich CM. Current understanding of the pathophysiology of systemic juvenile idiopathic arthritis (SJIA) and target-directed therapeutic approaches. Clin Immunol. 2015;159: 72-83.

2. Petty RE, Southwood TR, Manners P, et al; International League of Associations for Rheumatology. International League of Associations for Rheumatology classification of juvenile idiopathic arthritis: second revision, Edmonton, 2001. J Rheumatol. 2004;31:390-392.

3. Behrens EM, Beukelman T, Gallo L, et al. Evaluation of the presentation of systemic onset juvenile rheumatoid arthritis: data from the Pennsylvania Systemic Onset Juvenile Arthritis Registry (PASOJAR). J Rheumatol. 2008;35:343-348.

4. Ringold S, Weiss PF, Beukelman T, et al; American Collge of Rheumatology. 2013 update of the 2011 American College of Rheumatology recommendations for the treatment of juvenile idiopathic arthritis: recommendations for the medical therapy of children with systemic juvenile idiopathic arthritis and tuberculosis screening among children receiving biologic medications. Arthritis Rheum. 2013;65:2499-2512.

5. Kornstein SG, Keck PE Jr, Herman BK, Puhl RM, Wilfley DE, DiMarco ID. Communication between physicians and patients with suspected or diagnosed binge eating disorder. Postgrad Med. 2015;127: $661-670$.
Open Access Rheumatology Research and Reviews

\section{Publish your work in this journal}

Open Access Rheumatology Research and Reviews is an international, peer-reviewed, open access journal, publishing all aspects of clinical and experimental rheumatology in the clinic and laboratory including the following topics: Pathology, pathophysiology of rheumatological diseases; Investigation, treatment and management of rheumatological

\section{Dovepress}

diseases; Clinical trials and novel pharmacological approaches for the treatment of rheumatological disorders. The manuscript management system is completely online and includes a very quick and fair peerreview system, which is all easy to use. Visit http://www.dovepress.com/ testimonials.php to read real quotes from published authors. 